\title{
Las milicias antifascistas de Cataluña: aproximación a la problemática del armamento y a la cuestión financiera
}

\section{Resumen}

El artículo se centra en el análisis de las condiciones financieras y militares de Cataluña durante los meses posteriores a la victoria sobre los militares sublevados en Barcelona, en el contexto de la expansión y consolidación de la Guerra Civil española. Se aborda la capacidad financiera de las instituciones catalanas para sostener el esfuerzo de guerra, se aportan datos cuantitativos en relación al número total de los efectivos organizados y se ofrece una aproximación al estado y a la calidad del armamento disponible en ese territorio, así como a las problemáticas relativas a la adquisición o fabricación del equipo y material necesarios para organizar, de manera efectiva, la respuesta armada al ejército rebelde.

Palabras clave: Milicias antifascistas, Guerra civil, Columnas, Milicianos, Voluntarios

The anti-fascist militias of Catalonia: An approach to the problem of armaments and the financial question

\begin{abstract}
The article analyses Catalonia's financial and military conditions during the months after the victory over the military rebels in Barcelona, in the context of the expansion and consolidation of the Spanish Civil War. It addresses the financial capacity of the Catalan institutions to sustain the war effort and
\end{abstract}


provides quantitative data about the total number of organized troops. It also offers an approximation to the condition and quality of the weapons available and acquiring or manufacturing the equipment and materials to organize an effective armed response to the rebel Army.

Keywords: Anti-fascist militias, Civil war, Columns, Militiamen, Volunteerss

\title{
Introducción
}

\begin{abstract}
Licenciamiento de tropas. El presidente del Consejo de ministros, a petición del ministro de la Guerra, ha firmado la siguiente orden: Quedan licenciadas todas las tropas cuyos cuadros de mando hayan tomado parte en el movimiento sedicioso, quedando exentos de toda responsabilidad al abandonar las armas y, por tanto, teniendo la obligación de retirarse a su hogar. El ministro de la Guerra. (Gaceta de Madrid, 19 de julio de 1936)
\end{abstract}

Dos días antes de esta gaceta, el 17 de julio 1936, se había sublevado el ejército colonial que se mantenía en el ya reducido territorio del protectorado español en Marruecos. Este hecho no había causado una gran conmoción en el territorio peninsular, simplemente se trataba de un pronunciamiento más en la sucesión de hechos traumáticos que, de manera recurrente, se habían manifestado en España con el inicio del siglo XX: dictadura militar, estados de excepción, agitación revolucionaria, violencia política, diversos e infructuosos pronunciamientos militares de diferente signo político, insurrecciones populares, intentos de secesión territorial e instauración de un nuevo régimen político; la II República española había finiquitado, en el año 1931, a la monarquía borbónica.

Los intentos de modernización y los profundos cambios impulsados por la República generaron un escenario de enfrentamiento permanente entre los diversos actores sociales, económicos y políticos del país. La violencia política, sin ser un hecho novedoso, se incrementó con el transcurso de los años hasta un nivel de confrontación insostenible; la transformación a la que aspiraba parte de la población española se encontró con la oposición frontal de amplios estamentos sociales, y en especial de los que habían mantenido, hasta la fecha, el control de las instituciones del país. Por otra parte, los influjos de la situación política en Europa se instalaron en la península de manera notoria: de un lado los movimientos revolucionarios internacionalistas, tanto los socialistas en sus diversas facetas como los libertarios, gozaron de gran adhesión entre la población española; del otro, los movimientos autoritarios y fascistas se empezaron a articular de manera significativa a lo largo de toda la geografía nacional.

De esta manera, no es de extrañar que la propagación de la sublevación del protectorado a guarniciones en territorio peninsular provocase una reacción popular sin precedentes. Ya durante las primeras horas, especialmente a partir 
del 19 de julio, miles de afiliados de las organizaciones sindicales, socialistas y republicanas se organizaron para defenderse de la acción de los militares alzados en armas. La derrota de las guarniciones sublevadas en las principales ciudades del país, especialmente en Madrid, Valencia y Barcelona, provocó la desmovilización de las Primera, Segunda y Cuarta divisiones orgánicas del Ejército Republicano, y favoreció la suplantación de esta fuerza armada por las milicias populares, articuladas mediante la incorporación de miles de civiles voluntarios y miembros de las fuerzas de orden público, además de militares profesionales que se habían mantenido fieles al gobierno.

Si es cierto que los reveses militares fueron numerosos, la defensa de Madrid y la estabilización del frente aragonés son dos claros ejemplos de los buenos resultados que obtuvo este ejército de voluntarios durante las primeras semanas de la conflagración. El general Vicente Rojo, poco afecto a este modelo de organización militar, escribió en sus memorias que había sido un "suceso notable" que estas columnas pudieran llegar, venciendo resistencias y sosteniendo contraataques, al pie de las tres capitales aragonesas, hasta poder fijar un verdadero frente de combate (Guarner, 1980: 129): "Se ha de destacar la gran audacia de las columnas catalanas, aragonesas y levantinas en su marcha hacia Zaragoza, Huesca y Teruel, hasta dejar fijado un frente de combate." (Rojo, 1940: 316)

En cualquier caso, las milicias populares se han estudiado hasta la fecha de manera parcial y siempre dentro de procesos más amplios relacionados con la Guerra Civil española, pero nunca como hecho específico y complejo. Solo recientemente se han publicado algunos estudios monográficos centrados en estudios de caso (Mainar, 1998; Paz, 2001; Romero, 2017; Berger, 2018).

El presente artículo pretende ofrecer una nueva perspectiva de este momento histórico, obtenida fundamentalmente a partir del estudio de fuentes primarias y de documentación de archivo inédita, en el que se recoge la capacidad real de sostener el esfuerzo de guerra de Cataluña durante los meses iniciales de la conflagración armada.

El Centro Documental de la Memoria Histórica (en adelante CDMH) ha sido uno de los archivos sobre el cual se han centrado más esfuerzos. Contiene gran cantidad de información relativa al Comité Central de Milicias y a las columnas que combatieron en Aragón y Madrid. Por otro lado, se han analizado los 191.084 documentos del fondo de subsidios de milicianos, que actualmente se ubica en el Archivo Nacional de Cataluña (en adelante ANC). Del Archivo General Militar de Ávila (en adelante AGMAV) han sido de gran valor las actas del Consejo Ejecutivo de la Generalitat correspondientes a los meses de noviembre y diciembre de 1936. A partir de estas actas se ha podido dilucidar la tarea de la Conselleria de Defensa y las dificultades que implicó la falta de financiación, así como la cuestión de las armas de la retaguardia y la militarización de las milicias. Ha sido fundamental la información obtenida en el Archivo Montserrat Tarradellas i Macià (en adelante AMTM). Este archivo 
contiene un número considerable de las actas del Comité Central de Milicias Antifascistas correspondientes a los meses de agosto y septiembre, que han sido clave para entender las competencias que asumió, el funcionamiento y las problemáticas que tuvo que afrontar este comité. El fondo Tarradellas también ha proporcionado información de gran interés para entender los aspectos financieros relacionados con el mantenimiento de las columnas milicianas. El fondo de la CNT y de la FAI, conservado en el International Institute of Social History de Ámsterdam (en adelante IISH), ha sido utilizado de manera recurrente para abordar diversos aspectos relacionados con el Comité, las columnas y la posición personal de los hombres de la organización que ocupaban puestos de responsabilidad durante este periodo, así como de la misma organización.

Finalmente, ha sido de gran interés el Fondo José del Barrio, que se localiza en el archivo del Pabellón de la República de Barcelona. José del Barrio, hombre fuerte del PSUC y de la UGT en el frente de Aragón, conservó gran cantidad de documentos e informes que él mismo redactaba para el Comité de Guerra del PSUC-UGT en la retaguardia, a partir de los cuales se puede entender la evolución militar de la guerra durante los primeros meses de la contienda.

\section{El Comité Central de las Milicias Antifascistas: la creación del nuevo ejército de Cataluña}

El 20 de julio de 1936 se dio por finalizada la sublevación de los militares en Barcelona. Fuerzas de orden público, militares fieles al Gobierno y miembros de las organizaciones del Frente Popular y del sindicato CNT habían conseguido derrotar el golpe de Estado de Cataluña.

El decreto de formación de las milicias ciudadanas para la defensa de la República y la lucha contra el fascismo, formulado a propuesta de la Presidencia y de acuerdo con el Consejo Ejecutivo del Gobierno de la Generalitat, fue firmado por el presidente Companys ${ }^{1}$ y publicado en el Boletín Oficial de la Generalitat de Cataluña el 21 de julio de 1936.

Con este decreto se autorizaba la formación y el equipamiento de las primeras columnas de combatientes organizadas, que se dirigieron fuera del territorio catalán con el objetivo de presionar sobre la capital aragonesa, en manos de los sublevados. El decreto, aparte de manifestar implícitamente la voluntad de apoyar con material y personal técnico a las columnas de combatientes, les otorgaba legitimidad legal, ya que las autorizaba como fuerzas militares del Gobierno de Cataluña. Para organizar y coordinar estas fuerzas militares y para materializar la alianza antifascista se creó el Comité Central de Milicias

1 Miembro de ERC, fue ministro de Marina del Gobierno de la República española y presidente de la Generalitat de Cataluña. 
Antifascistas, organización legalmente abalada y financiada, en buena parte, por el Gobierno de la Generalitat (Berger, 2018: 142).

La primera acción del Comité fue la publicación del reglamento de las milicias antifascistas, a partir de la cual se formaron las columnas de voluntarios:

\begin{abstract}
Para reclutar elementos para las milicias antifascistas, las organizaciones que constituyen el Comité quedan autorizadas para abrir los correspondientes centros de alistamiento [...]. La organización militar de las milicias antifascistas se estructura en grupos de diez milicianos y un jefe. Cada diez grupos forma una centuria, comandada por un centurión. Tanto los grupos como las centurias estarán compuestos, si es posible, por milicianos de una sola organización. El mando será efectuado por las organizaciones respectivas [...]. ' (Reglamento interno de las milicias antifascistas de Cataluña, 22/07/1936)
\end{abstract}

El 23 de julio, a primera hora de la tarde, salían en dirección a tierras aragonesas las primeras columnas de combatientes organizadas desde el Comité.

En los momentos iniciales, las organizaciones antifascistas asumieron el rol de reclutamiento y control estadístico de sus militantes en las unidades de combate. La firma y el sello de las organizaciones validaba, ante el Comité, la figura del miliciano. La atomización relativa a la organización de la guerra duró pocos días. En la reunión del Comité del día 3 de agosto de 1936, se decidió que el control de las casernas dejaba de estar en manos de las organizaciones para pasar a las del mismo Comité, que recuperó el control de todas las casernas de la ciudad en beneficio del esfuerzo de guerra conjunto, y puso en funcionamiento un servicio de inspección de casernas con el objetivo de corregir deficiencias y abusos (Acta del Comité Central de Milicias Antifascistas, 03/08/1936).

El 16 de agosto se anunció la oficialización de la figura del miliciano, un reconocimiento que iba acompañado del correspondiente salario de diez pesetas diarias. A este efecto, se anunció la obligación de todos los milicianos movilizados de poseer un carné que acreditara su identidad y pertenencia a las milicias. La caserna de Pedralbes en Barcelona, rebautizada como Bakunin, asumió la centralización y el control de las acreditaciones. En las directrices se especificaba que solo tenían derecho a la adquisición de la documentación los milicianos movilizados en el frente (Informe del Barrio al Comité de Guerra PSUC-UGT, 24/09/1936). En cualquier caso, aun con la introducción del subsidio de guerra en las milicias populares, la condición de combatientes voluntarios de los miembros de las columnas se mantuvo hasta el decreto de militarización, aprobado en diciembre de 1936.

A partir del análisis de documentación de la oficina de subsidios del Comité Central de Milicias (ANC, legajos 314-496) 3 y de la sección de Administración

2 El Reglamento fue impreso en el dorso del carné de miliciano, obligatorio para todos los componentes de las milicias a partir del 16 de agosto de 1936.

3 España, Barcelona, Archivo Nacional de Cataluña (ANC), PS-Barcelona_Generalitat. Este fondo contiene los 191.084 documentos generados porla Secretaría de Estadística del Comitè Central de les 
y Contabilidad de la Conselleria de Defensa (Conselleria de Defensa de la Generalitat, 21/11/1936), podemos establecer para el mes de agosto la cifra de 23.000 combatientes distribuidos entre los frentes de Aragón y Baleares. Entre septiembre y octubre la cifra ascendió a 35.000 voluntarios en activo entre los frentes de Aragón y Madrid. ${ }^{4}$

El 31 de octubre se inició la movilización de levas obligatorias en Cataluña, en la fase preparatoria a la creación del nuevo Ejército Popular. Los datos sobre la situación de fuerzas en el frente de Aragón, a fecha de 29 de noviembre de 1936, sitúan la cifra en 35.194 hombres y mujeres (entre militares profesionales, soldados de leva, milicianos y servicios auxiliares o sanitarios), de los cuales 1.500 estaban en reserva en la retaguardia (Cenarro y Pardo, 2006: 24). Se debe tener en cuenta que para esas fechas se habían destinado al frente de Madrid alrededor de 10.000 efectivos que pertenecían a las milicias catalanas (Berger, 2018: 169). El 19 de enero de 1937, una vez militarizadas las columnas de voluntarios, el Ejército Popular de Cataluña disponía de 49.900 efectivos activos, de los cuales 47.319 se hallaban desplegados en el frente de Aragón (AMTM, Fondo Tarradellas, GC_62_E01_D23).

\section{La financiación de la guerra}

La financiación de la lucha armada contra los militares sublevados fue una de las cuestiones más relevantes que tuvo que afrontar el Comité, en primer lugar, y posteriormente la Conselleria de Defensa de la Generalitat de Catalunya. La disponibilidad financiera, prácticamente inexistente, para adquirir armamento, equipos y suministros, así como para garantizar el mantenimiento de los combatientes, fue uno de los grandes problemas para los dirigentes catalanes durante los once meses que asumieron las competencias de defensa de su territorio (Berger, 2018: 188). Por otro lado, el Gobierno central, poco satisfecho por la pérdida de control político del territorio catalano-aragonés, limitó hasta el extremo el apoyo económico a la Generalitat de Catalunya.

Inicialmente se trató de proporcionar alimentos y otros suministros a las columnas. A partir del 16 de agosto de 1936 fue necesario asumir también los subsidios de los combatientes. La aplicación de esta medida se hizo con carácter retroactivo al 23 de julio de 1936. El aumento proporcional de los combatientes, especialmente a partir del decreto de movilización, implicó una carga económica de grandes proporciones. La necesidad de armamento y suministros de todo tipo aumentó, de manera gradual, el desgaste económico del Comité y de la Generalitat.

MilíciesAntifeixistes de Catalunya, en su mayoría subsidios de guerra que se generaron en relación con el cobro de 10 pesetas al día por parte de las y los voluntarios de las milicias organizadas en Barcelona. Estos documentos incluyen el nombre y lugar de residencia del combatiente, la organización política que lo avala, la columna, función y frente de destino.

4 El mes de septiembre fue de mucha actividad en cuanto a la formación de nuevas columnas. 
Las formas a través de las cuales se financió la guerra durante los primeros meses fueron tres: los donativos y recaudaciones; las confiscaciones de depósitos bancarios y otros valores a los ciudadanos considerados enemigos de la causa antifascista; y las apropiaciones de fondos del Estado depositados en la oficina de la Agencia Tributaria Española.

Como se ha dicho, parte de la financiación para el pago de las milicias catalanas llegó en forma de recaudaciones y donaciones de sindicatos, entidades y particulares, que en la medida de lo posible aportaron cantidades económicas en metálico para ayudar al esfuerzo de la guerra. Las adhesiones a las milicias antifascistas fueron muy amplias y llegaron desde todos los rincones del país y desde todos los sectores de la sociedad catalana. Se organizaron festivales y actividades de todo tipo con la finalidad de apoyar a las milicias. Se creó la oficina recaudatoria del Comité Central de Milicias Antifascistas con el objetivo de recoger las donaciones de la sociedad civil. Desde Radio Asociación de Cataluña se hacían públicas las cantidades que llegaban diariamente (Auto del Comité Central de Milicias Antifascistas, 08/09/1936). El domingo 23 de agosto se celebraron en Cataluña diecisiete festivales o fiestas en beneficio de las víctimas del fascismo y las milicias antifascistas. Se recaudaron 30.411 pesetas. El 9 de septiembre ya se habían recaudado, mediante donativos, 2.048.447 pesetas. El 16 de septiembre la cifra llegó a 2.554.251 pesetas. El 21 de noviembre de 1936 la cifra recibida en la oficina para este concepto ascendía a 6.596.747 pesetas (Relación de donativos ingresados en el comité de milicias antifascistas, acumulado 25/08/1936, 09/09/1936, 16/09/1936, $21 / 11 / 1936)$. Pero las necesidades de la guerra -durante los primeros meses aún relativamente pequeñas- exigían una cantidad de recursos muy por encima de lo que las recaudaciones podían atender.

Otra línea de financiación fue la confiscación por parte del Comité de depósitos bancarios, además de la requisa de joyas y obras de arte de personas consideradas enemigas de la causa antifascista. Es el caso de los depósitos de la caja fuerte del Banco de Vizcaya, propiedad de los hermanos Juan y Ricardo NubiolaVilumara y de Abraham Adjiman (CDMH, Delegación Nacional de Servicios documentales de la Presidencia de Gobierno, Fondo PS_MADRIDC1563_EXP020_F001 y F002). El resto del financiamiento para mantener al ejército llegó a través de transferencias de la Generalitat de Catalunya, que a su vez había expropiado los fondos de la Delegación de Hacienda del Gobierno español en Cataluña (AMTM, Fondo Tarradellas, GF-20_E01_12). Entre el 27 de julio y el 31 de agosto, los pagos realizados por la Delegación de Hacienda del Gobierno republicano en Barcelona por imposición de la Generalitat a favor de terceros y con destino específico fueron de 6.685.169 pesetas (AMTM, Fondo Tarradellas, GF-20_E01_20).

De la falta de recursos financieros resultó que los impagos y los retrasos fueran la dinámica habitual. Durante la reunión del Comité del día 31 de agosto se acordó pagar sin demora las facturas pendientes de los proveedores de materiales y suministros, a fin de resolver los problemas con varios industriales y 
comerciantes que se encontraban en situación precaria por culpa del impago que sufrían por parte del Comité. Se delegó en Soler la revisión de las facturas y, bajo su conformidad, se debía autorizar el pago con los fondos de los que disponía el Comité o con los que pudiera hacer efectivos la Generalitat (Acta del Comité Central de Milicias Antifascistas, 31/08/1936).

Joan García Oliver ${ }^{5}$ describió la situación precaria en la que se encontraba el Comité durante aquellos días:

El problema era complejo. Cataluña estaba sola para afrontarlo [...] treinta mil con un salario de 15 pesetas diarias, más los municionamientos, exigían muchos millones. Y del dinero no disponía el gobierno de la Generalitat, sino el gobierno de Madrid. Habría un consumo de municiones y un desgaste de armamentos que habría que reponer. El gobierno de la Generalitat y el gobierno de Madrid carecían de ambas cosas. Habría que obtenerlas en el extranjero, con oro o con divisas, de los que solamente podía disponer el gobierno de Madrid. Podríamos, ciertamente, afrontar una transformación parcial de la industria catalana en industria de guerra; pero para la adquisición de materias primas indispensables y el pago de salarios haría falta dinero, que era difícil saber de dónde saldría. Por nuestra parte, anarcosindicalistas, en lo que se refería al dinero, teníamos lo justo para la compra del día. El dinero estaba en los bancos, que hubiéramos podido tomar de haber ido a por el todo, pero que hubimos de dejar donde se encontraba. Después, a medida que se fueron generalizando las incautaciones de fábricas, talleres y comercios, los depósitos bancarios de las sociedades afectadas pasaron a ser elementos de gestión en el trabajo. (García Oliver, 1978: 197-198)

A inicios de octubre, el Comité Central de las Milicias Antifascistas había sido disuelto y todas sus funciones, tanto las de orden público como las de defensa, habían sido traspasadas al Gobierno de la Generalitat. A finales de ese mes, la necesidad de armamento y suministros para una fuerza cada vez más numerosa había provocado un déficit insostenible para el Gobierno catalán.

Durante la reunión del 18 de noviembre del Consejo Ejecutivo, el conseller Josep Tarradellas ${ }^{6}$ expresó la angustiosa situación en que se encontraban las finanzas y los graves problemas de tesorería que se le presentaban. Tarradellas era de la opinión de que no podían continuar pidiendo créditos al Estado, ya que estos representaban una gran carga financiera (Actas del Consell Executiu de la Generalitat de Catalunya, 18/11/1936). Efectivamente, el esfuerzo de la guerra que mantenía Cataluña era financiado por la Generalitat a través de créditos que otorgaba el Banco de España con el aval del Gobierno republicano. Aun así, la situación era delicada, ya que los créditos otorgados a partir del mes de octubre eran insuficientes y muy costosos financieramente.

Un informe firmado por el conseller y por el jefe de la Sección Económica, Administración y Contabilidad (Consejería de Defensa de la Generalitat,

5 Fue un miembro destacado de la CNT. Ocupo la Secretaría de Guerra y Operaciones del CCMA y fue nombrado subsecretario de la Conselleria de Defensa de la Generalitat. Posteriormente fue nombrado ministro de Justicia del Gobierno de la Segunda República.

6 Militante destacado de ERC, fue diputado en las Cortes Españolas y del Parlamento de Catalunya. Entre 1931 y 1939 ocupó las consejerías de Sanidad, Gobernación, Servicios Públicos y Economía del Gobierno de la Generalitat de Catalunya. 
21/11/1936), fechado el 21 de noviembre de 1936, dejó evidencia de que se necesitaban 27.500.000 pesetas para cubrir los gastos del mes de noviembre y liquidar la deuda acumulada de los meses anteriores. Había que atender pagos por un importe de 27.330.938 pesetas, y los últimos movimientos de caja eran muy claros respecto a las cuentas de la Conselleria: solo se disponía de 622.403 pesetas. El Gobierno catalán se encontraba al borde del colapso financiero. Varias columnas de milicianos no habían cobrado desde el mes de septiembre y los proveedores del Ejército también estaban a la espera de la liquidación de facturas, hecho que afectaba negativamente a la economía del país. La situación en el frente y en la retaguardia era compleja, y la guerra incrementaba día a día la demanda de recursos.

El 25 de noviembre, el conseller Tarradellas expuso en el Consell de la Generalitat el resultado de la reunión mantenida en Valencia con Negrín, ministro de Hacienda del Gobierno de la República, y Nicolau d'Olwer, gobernador del Banco de España. Dada la situación crítica que expuso Tarradellas sobre las finanzas catalanas, Negrín sugirió que el Banco de España les otorgara un crédito avalado por el Estado. Tarradellas se resistía, ya que consideraba que podía representar una carga "demasiado pesada" para el futuro del pueblo de Cataluña, aunque acabó su intervención reconociendo que la única salida que tenían era que el Estado les otorgara un crédito. Finalmente, se acordó tramitar en el Banco de España un crédito de cincuenta millones de pesetas y solicitar al tesoro español un crédito de doscientos millones de pesetas. Durante esta reunión Tarradellas también expuso las dificultades que tenía la Generalitat para obtener divisas a través del Centro de la Contratación de la Moneda del Banco de España. Este hecho dificultaba gravemente la rapidez de las transacciones para la adquisición de material de guerra y materias primas para la industria catalana (Actas del Consell Executiu de la Generalitat de Catalunya, 25/11/1936). El día 2 de diciembre, Tarradellas informó al Consell que el ministro Negrín había autorizado un crédito de treinta millones de pesetas, en lugar de los doscientos cincuenta que había pedido la Generalitat (Actas del Consell Executiu de la Generalitat de Catalunya, 02/12/1936). A finales de diciembre se recibió la transferencia de treinta millones de pesetas en la forma de un crédito bancario, con unas condiciones de pago y unos intereses que agravaban la situación de Cataluña. Los treinta millones serían para tapar el agujero de noviembre, pero mantenían en la precariedad al Gobierno de Cataluña. En enero de 1937 la situación financiera aún era muy tensa. Se volvió a tramitar un crédito de guerra por valor de 48.500 .000 pesetas, que fue concedido el 12 de enero. Con este importe se abonaron los subsidios pendientes y otras facturas del mes de diciembre, por valor de 34.058.811 pesetas.

La necesidad constante de material de guerra y suministros para un ejército cada vez más numeroso hizo insostenible el mantenimiento de la guerra por parte de la Generalitat de Catalunya. Si los subsidios de los combatientes representaban, con diferencia, el porcentaje más elevado del coste de la guerra, el resto de las facturas por abonar no era menos importante. El aumento del gasto se produjo a partir del mes de octubre, principalmente de noviembre 
hacia adelante, coincidiendo con la formación del Ejército Popular de Cataluña, que tenía que sustituir a las columnas de milicianos. El 23 de abril de 1937, pocos días antes de los acontecimientos conocidos como "los hechos de Mayo", la situación financiera era de colapso. Desde septiembre de 1936 hasta el 23 de abril de 1937 se contabilizó un gasto asociado a las industrias de guerra -excluyendo el pago de los sueldos de los combatientes, compra de armamento y materias primas en el extranjero y otros suministros- al servicio del Ejército de Cataluña de 96.230.464 pesetas en facturas, de las cuales se habían abonado con muchas dificultades 61.929 .661 pesetas. Faltaban por pagar a diferentes proveedores 34.400 .803 pesetas (Detalle del total de facturas entradas hasta la fecha, 21/04/1937).

\section{Armas para una guerra}

Según el historiador José Luis Alcofar Nassares, en julio de 1936 en Cataluña se disponía de 51.150 fusiles (Alcofar Nassares, s/fecha). Las fuerzas armadas y las fuerzas de orden público contaban con 18.150 fusiles y mosquetones máuser, y en los depósitos del parque de la 4. a División había otros 33.000 más, a los que había que añadir 286 ametralladoras y 262 morteros de infantería. La artillería disponible contaba con 136 unidades: 16 del modelo Krupp 70/16, para acompañamiento; 36 del tipo Schneider 75/28, para campaña; 36 obuses Vickers 105/26; 24 obuses de montaña 105/11 y 24 obuses Schneider 155/13. A estos se les debía añadir 100 piezas que había en el depósito del parque divisionario, pero que eran modelos muy antiguos, entre los cuales se contaban 24 unidades Krupp que se habían utilizado en la batalla de Alcolea, en el año 1868, y que fueron destinados a la defensa de costas. En relación con la aviación, Cataluña disponía de la fuerza de la 3. Escuadra, la más débil de toda la península. La escuadra estaba compuesta por nueve Breguet 19, de los cuales cinco estaban operativos, y ocho Niuport 53, tres de los cuales estaban operativos. A estos se sumaban los hidroaviones de la aeronáutica naval: quince Machi 18, trece Savoia S-62 -de los cuales cinco estaban en Mahón-, un Dornier y un Vickers, para un total de treinta hidroaviones.

A todas luces, el armamento disponible en Cataluña en julio de 1936 resultaba del todo insuficiente para afrontar, con un mínimo de garantías, la consolidación defensiva del territorio catalán y la recuperación de Zaragoza -y el resto de las capitales de provincias aragonesas- y de las Baleares. El esfuerzo para armar al nuevo ejército catalán fue la prioridad del Comité, en primera instancia, y de la Conselleria de Defensa de la Generalitat de Catalunya, posteriormente, y hasta mayo de 1937, momento en el que el Gobierno republicano recuperó las competencias en defensa e interior del territorio catalán y, por extensión, la de los frentes de Aragón y las Baleares.

El tratado de no intervención, aplicado a partir del 8 de agosto y ratificado el 9 de septiembre de 1936, paralizó la compra legal de armas por parte de los 
Gobiernos de la República y de la Generalitat a las democracias europeas. A los delegados de estas instituciones designados con esa finalidad no les quedó otra alternativa que recurrir a los traficantes del mercado negro para equipar a las nuevas unidades de combatientes. A partir de la segunda quincena de agosto de 1936 la compra de armamento se hizo de manera ilegal, principalmente a través de la frontera francesa o por vía marítima hacia los puertos de Barcelona o Valencia, como se observa en la documentación que se conserva en el Archivo Tarradellas i Macià relativa a la propuesta de compra de armas al traficante Pierre Robert a inicios de septiembre de 1936:

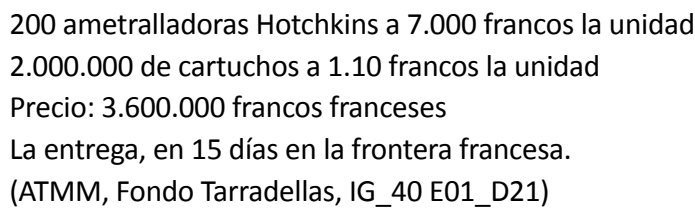

En relación a esta operación de adquisición de armamento de guerra por parte de las autoridades catalanas, se observa que se trató de una suma económica realmente importante para la época, lo que indica claramente cuáles eran las prioridades del Comité para mejorar la situación del frente de Aragón: ametralladoras y cartuchos.

Paralelamente a la adquisición de material y equipo de guerra en el mercado negro, el Gobierno de la Generalitat procedió a reconvertir la potente industria catalana en una industria de guerra eficaz. Se consiguieron grandes avances, pero la problemática para conseguir materia prima -fundamentalmente a través de la disposición de divisas extranjeras, que tenían que ser facilitadas por el Banco de España- fue constante y lastró gravemente la capacidad militar de Cataluña durante los meses iniciales de la conflagración.

Eugenio Vallejo, del Sindicato de la Metalurgia de la CNT de Barcelona, fue designado por el Comité para articular y poner en funcionamiento la industria de guerra catalana. El coronel Giménez de la Beraza $^{7}$ y el comandante Vicenç Guarner ${ }^{8}$ tenían que ayudar en los aspectos técnicos relativos al armamento. Lluís Prunés, ${ }^{9}$ consejero de la Generalitat de Catalunya, tenía que financiar el proyecto. Previamente se había encargado la tarea a Francisco Ferry Linder; ${ }^{10}$

7 En 1936 era coronel de artillería y exdirector de la fábrica de armas de Oviedo. Fue agregado militar del CCMA. Organizó la agrupación de artillería de Cataluña y la Comisión de Industrias de Guerra de la Generalitat.

8 Participó en la Guerra de Marruecos con la graduación de capitán, posteriormente fue profesor de la Academia Militar de Infantería de Toledo y de táctica en la Escuela Superior de Guerra de Madrid. En 1935 fue nombrado jefe de los Servicios de Orden Público de la Generalitat. Formó parte del CCMA como asesor técnico y fue subsecretario de la Conselleria de Defensa de la Generalitat. En 1937 fue jefe de las fuerzas del frente de Aragón y jefe del Estado Mayor del Ejército del Este. En 1938 fue nombrado director de la Escuela Popular de Estado Mayor.

9 Militante de ERC. Fue alcalde de Manresa, gobernador civil de Girona y comisario de Orden Público en Tarragona. Ocupó la Conselleria de Economía, la de Agricultura y la de Trabajo del Gobierno de la Generalitat.

10 Miembro del Partido Comunista de Cataluña y posteriormente del PSUC. El 21 de julio de 1936 fue nombrado miembro del Comité de Guerra de la Generalitat de Catalunya. 
el 1 de agosto había sido nombrado por el Departamento de Gobernación de la Generalitat de Catalunya jefe de los Servicios Técnicos Militares, con facultad para la construcción y la conservación de armas y artefactos de guerra, y con esta finalidad le concedieron la máxima autoridad, a la que se veían obligados a someterse todas las organizaciones antifascistas. Ferry adquirió en Francia, de manera ilegal, el armamento y la materia prima necesaria para la construcción de blindados en Cataluña, pero al regresar de su primer viaje al extranjero había sido sustituido por el anarcosindicalista Vallejo. Ferry explica en sus memorias que adquirió una partida de bombas Bregueten Tolosa, enviada por vía aérea a Barcelona (Feldman, 1956). También narra que cerró la adquisición de una gran cantidad de explosivo TNT y camiones comprados mediante Bélgica y embarcados desde Holanda hasta al puerto de Valencia, pero que fracasó en las negociaciones con el director de Air France, que no accedió a vender aviones de guerra.

La actividad del frente de Aragón se paralizó progresivamente, principalmente a causa de la falta de armamento, municiones y otros suministros esenciales para la guerra. Desde la retaguardia se intentaba justificar el estancamiento y la no consecución de los objetivos militares con la cuestión del mando único y la disciplina, pero la realidad era que a menudo los milicianos solo disponían de treinta cartuchos al día. Tampoco se disponía de fusiles, y con frecuencia contingentes de voluntarios tenían que ser devueltos a sus casas, en tanto no se los podía armar convenientemente. La pólvora que utilizaba la industria catalana era pólvora con humo, que obturaba los cañones de los fusiles. ${ }^{11}$ Las ametralladoras y los cañones eran escasos y disponían de poca munición. El transporte de tropas y suministros era precario. El miliciano Manuel Hernández recuerda que la situación era insostenible: "Cuando nos enviaban ametralladoras, ya no teníamos municiones. Y cuando llegaban las municiones, las ametralladoras estaban rotas." (Magnus, 1998: 172)

El general Walter Germanovich Krivitsky, jefe militar del Servicio de Inteligencia de la URSS en Europa occidental desde 1935 hasta 1937, fue el encargado de suministrar armamento al Gobierno de la República, tanto de origen soviético como de otros países europeos. En sus memorias dejó clara la política de los comunistas de no enviar armamento a Cataluña bajo ningún concepto:

Por todo el mundo se extendía un clamor de fuerte angustia por el bombardeo sin piedad del indefenso Madrid. Mi organización obró milagros en el rápido transporte de los cincuenta aviones de caza y bombardeo. A mediados de octubre se cargaron en un barco noruego. Entonces recibí instrucciones concretas de Moscú de no permitir que el barco dejase su cargamento en Barcelona. Bajo ninguna circunstancia estos aviones debían pasar por Cataluña que tenía su propio gobierno dentro de España y era muy parecido al de un Estado independiente. El gobierno de Cataluña estaba dominado por revolucionarios de convicciones antiestalinistas. Moscú no tenía confianza con ellos, aunque defendían desesperadamente uno de los sectores más vitales del frente gubernamental contra terribles ataques del ejército de Franco. (Krivitsky, 1946)

11 En sus respectivas memorias, Juan García Oliver y Vicente Guarner destacan el inconveniente de la pólvora como el problema principal que tuvieron que afrontar al frente de las milicias catalanas. 
El informe de José del Barrio al Comité de Guerra del PSUC-UGT, fechado el 27 de octubre, habla de manera muy clara sobre la situación de los suministros en el frente de Aragón:

\begin{abstract}
Si nosotros seguimos por el camino emprendido extendiendo nuestras fuerzas, no relevándolas nunca, gastando sus energías, perdiendo continuamente hombres por heridas o por enfermedades, mal abrigadas y municionadas, no hay duda de que en alguna de las futuras ofensivas del enemigo este estará en inmejorables condiciones de cumplir sus objetivos. (Informe de José del Barrio al Comité de Guerra PSUCUGT, 27/10/1936)
\end{abstract}

Un informe sobre el estado del frente de Aragón y del armamento disponible en aquel punto presenta una situación realmente crítica durante el mes de noviembre de 1936. Se disponía en todo el frente de 29.780 fusiles, 162 fusiles ametralladores, 187 ametralladoras, 74 morteros de 50 milímetros, 7 morteros de 81 milímetros, 7 piezas de artillería y 16 camiones blindados (IISH, Fondo CNT, Miguel González Inestal, 28A).

Entre septiembre y noviembre gran cantidad de efectivos, equipos y prácticamente todas las piezas de artillería disponibles habían sido desplazados al frente del centro y participaban de la defensa de la capital (Berger, 2018: 188). Una vez desplegados allí fueron bien abastecidos y municionados. Un ejemplo es el de las dos baterías del 7.5 bajo el mando del capitán Jesús del Prado, desplegadas en el frente de Aragón desde el día 1 de agosto y enviadas al frente de Madrid a inicios de noviembre, desplegándose el 16 de ese mes en el sector de Dehesa de la Villa, donde participaron en los ataques sobre Garabitas, la Casa de Velázquez y la carretera de la Coruña. Tomaron parte en los combates en primera línea sin interrupción hasta el día 10 de diciembre de 1936, y a partir de aquel momento en intervalos constantes hasta el 6 de abril de 1937, día en que, por orden de la Conselleria de Defensa, las baterías se entregaron a la Comandancia Principal de Artillería de Madrid. Entre los días 24 de julio de 1936 y 2 de abril de 1937, las baterías utilizaron 22.008 proyectiles, de los cuales 19.876 fueron utilizados en la defensa de Madrid y 2.132 durante la ofensiva de Aragón (Diario de operaciones de la Batería Ligera de la columna Durruti, Frente de Madrid, 14/05/1937).

A los efectivos y material destinado al frente de Madrid se han de sumar las ingentes cantidades de equipo que se perdieron tras la precipitada retirada del frente de Mallorca, la noche del 3 al 4 de septiembre de $1936 .{ }^{12}$ Según el informe que efectuó el jefe de las fuerzas sublevadas en Mallorca, el coronel José Luis García Ruiz, las fuerzas de Bayo dejaron en la isla 2 camiones blindados, 4 obuses de montaña del 105, 8 cañones de campaña del 75, un mortero de 81 milímetros, 3 de 60, 4 de 50, 22 ametralladoras Hotchkiss, 2 Vickers para aviación y 320 cajas de munición para ametralladora. También

12 Los combates en la isla implicaron 4.500 efectivos organizados en Cataluña y se prolongaron entre el 16 de agosto y el 3 de septiembre de 1936. 
había 2.709 fusiles máuser y 703.345 cartuchos de fusil, 1.638 granadas de mano Laffitte, 77 para mortero del 81, 1.772 para mortero del 50, además de otros tipos de munición y equipo diverso, así como grandes cantidades de alimentos, suministros básicos y equipos sanitarios (Diario de operaciones del coronel José Luis García Ruiz, 08/10/1936). En este sentido la expedición fue un auténtico fracaso, ya que no estaba en disposición de reponer el material abandonado, especialmente la cartuchería.

Es un hecho recurrente, entre todos los testimonios de las fuerzas que luchaban en Aragón, que las centurias cuando eran relevadas de la primera línea dejaban las armas a los milicianos que las sustituían. En lo que a uniforme y ropa de abrigo se refiere, las milicias también eran absolutamente deficitarias. Además, el traslado al frente era penoso. Se hacía mediante ferrocarriles lentos y abarrotados de milicianos, a menudo ocupados en el envío de suministros al frente.

Diego Abad de Santillán hace referencia a la situación de las armas disponibles en el frente de Aragón:

\begin{abstract}
Lo que teníamos en Aragón no era más que una débil línea de observación. Treinta mil fusiles, veinte o veinticinco baterías y algunas ametralladoras, no era material suficiente para una línea tan extensa. No podemos acallar el hecho de que mientras en el frente de Aragón solo teníamos treinta mil fusiles, en la retaguardia, en poder de los partidos y organizaciones había alrededor de sesenta mil, con más munición que en el frente, donde estaba el enemigo.
\end{abstract}

Y continúa:

\begin{abstract}
Las quejas de los combatientes eran continuas, ruidosas y justificadas. Durruti, cada vez que llegaba a Barcelona y veía tantas armas por la calle, rugía como un león. Un día supo que en Sabadell había ocho o diez máquinas ametralladoras. Las pidió de buen grado y se las negaron. Entonces organizó una centuria y la envió a Sabadell a buscar por la fuerza lo que no se quería entregar a la guerra voluntariamente. Estas ametralladoras estaban en manos de los comunistas, pero en Barcelona había quizás cuarenta máquinas en manos de los propios compañeros. En todo el frente de Aragón no teníamos tantas. (Abad de Santillán, 1940: 90-91)
\end{abstract}

El problema de las armas en la retaguardia no solo fue un asunto de orden público en Cataluña; representó un problema de fondo para el desarrollo de las milicias catalanas en el frente. De este hecho fueron responsables todas las organizaciones políticas y fuerzas de orden público catalanas.

El 11 de noviembre de 1936, el jefe del Gobierno de la Generalitat, Josep Tarradellas, rindió cuentas al Consell Ejecutivo de la Generalitat sobre el viaje que había hecho el día anterior a París. El jefe del Gobierno expresó las dificultades que los comisionados de la Generalitat tenían para adquirir material de guerra en Francia, a pesar de que creía que en breve se recibiría alguna cantidad (Actas del Consejo Ejecutivo de la Generalitat de Catalunya, 
11/11/1936). Durante la misma reunión, Tarradellas también informó que Caspe y Barbastro reclamaban cantidades crecientes de suministros para "nuestras tropas", y que la Generalitat les proveía de todo lo que necesitaban. Indicó que era necesario crear una intendencia militar para mejorar la capacidad de abastecer a los milicianos.

Durante la reunión del 25 de noviembre, el conseller Comorera explicó que tenía un informe del Comité de Control de los Ferrocarriles en el que se exponía que la falta de carbón y materiales para reparar las máquinas podía llevar, en breve, a la paralización del tráfico ferroviario en todo Cataluña (Actas del Consejo Ejecutivo de la Generalitat de Catalunya, 25/11/1936). Tal era la precariedad y la fragilidad de la industria de guerra catalana y el abastecimiento del frente.

\section{La cuestión de la pólvora}

A pesar del escaso y anticuado armamento del que se disponía en Cataluña, el principal problema lo representaba la escasa reserva de cartuchos, que el 21 de julio de 1936 se situaba alrededor de las 750.000 unidades. Los miembros del Comité enseguida observaron la grave carencia que esto implicaba y las dificultades que suponía a la hora de sostener los frentes de guerra.

Durante el pleno del Comité del día 4 de septiembre de 1936, el coronel Giménez de la Beraza hizo una referencia especial a la falta de cartuchos, la conveniencia de proceder a la requisa de existencias en todo Cataluña y la necesidad de fabricar pólvora con urgencia. Se tuvo en cuenta que para poder fabricarla hacía falta un mínimo de dos meses. Durante la misma reunión Guarner informó que para la toma de Huesca hacían falta un millón de cartuchos (Actas del Comité Central de Milicias Antifascistas, 04/09/1936). García Oliver reconocía que el Comité no estaba en disposición de suministrar este material a las fuerzas de Aragón. Según explica García Oliver en sus memorias, la industria de guerra catalana se puso en funcionamiento pronto y con eficiencia. Se produjeron granadas de mano cargadas con dinamita, bombas de aviación cargadas con cordita y proyectiles de artillería. Según la versión de García Oliver (1978), se llegaron a producir 100.000 cartuchos diarios con bala y detonador para fusil y ametralladora, pero sin pólvora. Este fue el gran problema de la industria de guerra catalana. Se producía pólvora con humo, inservible para cartuchos. No se disponía de los equipos necesarios para la producción industrial de este componente.

En España solo existían dos fábricas con capacidad para producir la tan necesaria pólvora: la primera en Granada, en manos de los sublevados; la segunda en Toledo, en poder del Gobierno republicano. El comité recibió una pequeña cantidad de pólvora sin humo del Gobierno republicano y se utilizó también un pequeño depósito situado en la caserna de la Maestranza de Barcelona. A 
finales de septiembre la situación era desesperada. Según García Oliver, las unidades en el frente tenían cartuchos para aguantar un ataque del enemigo durante tres o cuatro horas de combate, pero no más. La solución adoptada fue utilizar los depósitos de la pólvora con humo fabricada en los talleres de pirotecnia de Cataluña. Se daba el caso de que un fusil podía realizar entre cuarenta y cincuenta disparos con este tipo de pólvora. Después tenía que limpiarse. Se reservaron los cartuchos buenos para las ametralladoras y se dieron órdenes a todas las columnas de paralizar las acciones en el frente (García Oliver, 1978).

El día 13 de noviembre, Tarradellas informó al Consejo Ejecutivo de la Generalitat la oferta que había recibido desde Albania: se trataba de la compra de doce millones de cartuchos Skoda. Se acordó enviar un comisionado a la ciudad de Spolato para negociar la compra. Desde Polonia también llegaban ofertas de material de guerra, y durante la reunión se acordó el envío de un delegado para verificar las mercancías (Actas del Consejo Ejecutivo de la Generalitat de Catalunya, 13/11/1936).

El día 2 de diciembre, el conseller de Defensa anunció al Consejo Ejecutivo de la Generalitat que las actividades en el frente de Aragón se encontraban totalmente paralizadas por la falta de cartuchos (Actas del Consejo Ejecutivo de la Generalitat de Catalunya, 02/12/1936). La escasez de municiones se hizo evidente en las conversaciones mantenidas entre el jefe de la Conselleria de Orden Público y el delegado de las Industrias de Guerra de la Conselleria de Defensa. El 26 de enero de 1937 el jefe de Orden Público solicitó que se le devolvieran los 100.000 cartuchos máuser de $7 \mathrm{~mm}$ que anteriormente se habían cedido para ser destinados al frente. La respuesta de la Conselleria fue negativa: no era posible devolver la munición (Informe del coronel comandante principal del departamento técnico de artillería al Conseller de Defensa, 27/02/1937). A partir del mes de febrero de 1937 la industria catalana empezó a producir pólvora sin humo.

A pesar del esfuerzo para adaptar la industria catalana a las necesidades de la guerra, el Gobierno republicano mantuvo un constante juego de presión sobre Cataluña. El 12 de marzo de 1937, el comisario de Carbones del Departamento de Economía comunicó al consejero de Defensa que las reservas de carbón para abastecer las industrias de guerra solo durarían una semana, y que frente a la imposibilidad de conseguir moneda extranjera -el mercado internacional del carbón funcionaba con libras esterlinas- para contratar vapores y comprar materia prima, la producción se tendría que detener. El comisario informó al conseller que en su momento se habían depositado en el Banco de España los valores suficientes para adquirir divisa extranjera, sin que hasta ese momento este hubiera hecho la transacción necesaria (Informe del comisario de carbones del Departamento de Economía y Servicios Públicos de la Generalitat, 03/03/1937).

El 6 de mayo de 1937, y como consecuencia directa de los "Hechos de Mayo", el Ejército Popular de Catalunya pasó a denominarse Ejército del Este, bajo 
mando directo del general Pozas, y procedió a encuadrarse en la estructura orgánica del Ejército Popular de la República (Aguilera, 2012), marcándose el inicio de una nueva etapa para estas fuerzas que culminaría los últimos días de diciembre de 1937 con la Batalla de Teruel.

\section{Conclusiones}

A pesar de las dificultades financieras, el bloqueo del armamento, la complejidad de la situación en la retaguardia y el enfrentamiento con un ejército profesional bien equipado y organizado, los responsables políticos de articular la defensa de Cataluña fueron capaces de crear un ejército desde la base y resistir a la presión militar de un enemigo experimentado. Pese a la poca compactación estructural, la diversidad ideológica y la falta de medios bélicos, se consiguió movilizar y equipar una fuerza militar operativa y un número de combatientes que aumentó exponencialmente a medida que los meses transcurrían. Durante el mes de agosto el total de la fuerza se situó en torno a los 20.000 milicianos, en septiembre llegó a los 35.000, y en noviembre a los 45.000. Paralelamente, se trabajó en la creación del Ejército Popular de Cataluña y en la transformación de la industria catalana en una industria de guerra eficaz.

Al mismo tiempo, estas fuerzas obtuvieron destacados éxitos militares: defendieron las fronteras catalanas, recuperaron gran cantidad del territorio aragonés bajo control de los sublevados y participaron con gran determinación en la defensa de la ciudad de Madrid. El intento de liberar las Islas Baleares resultó un fracaso, con graves consecuencias políticas y militares para Cataluña.

Aun así, el frente de Aragón se situó cerca del colapso militar, ya que no disponía de los combatientes necesarios ni de los equipos y armamentos adecuados, ni siquiera para mantener una defensa efectiva. La cuestión de los cartuchos, ante la incapacidad de producir o adquirir pólvora sin humo, llegó a extremos insostenibles e incluso se dio el caso de que, durante algunas semanas del mes de octubre, grandes extensiones del frente de Aragón no estaban en condiciones de resistir un ataque más allá de tres o cuatro horas, por falta de munición. Esta realidad implicó la posibilidad de la derrota total de las fuerzas catalanas.

Aunque la situación respecto a los equipos y suministros mejoró a partir de marzo de 1937, no fue hasta la consecución del encuadramiento de las unidades catalanas en el Ejército Popular de la República que se dispuso de armamento y equipo suficiente para mantener una defensa activa, incluso dibujándose la posibilidad de realizar operaciones ofensivas de mayor calado, aunque para esas fechas los dos ejércitos en liza ya habían conseguido articular gran cantidad de contingentes humanos y disponían de una capacidad de fuego que acabó resultando devastadora (Alegre, 2018). 
Cabe preguntarse si la incapacidad para equipar convenientemente y en primera instancia a los voluntarios organizados en Cataluña y, en consecuencia, la pérdida de objetivos prioritarios y decisivos como lo eran Zaragoza y las Baleares, no representó un error garrafal en la estrategia de guerra adoptada por el Gobierno republicano, que tuvo como desenlace la victoria de los sublevados. A su vez, es necesario analizar los motivos de fondo que generaron la desconfianza del Gobierno republicano hacia la autonomía catalana y que se tradujo en la asfixia económica y militar de esta. De igual manera, y más allá de cuestiones que ocuparon la centralidad en el debate político, como la militarización de las milicias, el mando único, la autonomía política de los diferentes territorios o el modelo económico a desarrollar, la realidad era que, como consecuencia del pacto de no intervención firmado el 8 de agosto de 1936 y hasta la llegada masiva de material de guerra soviético a partir del año 1937, las fuerzas contrarias a la sublevación cívico militar del 17 de julio de 1936 no tuvieron ninguna opción real de obtener la victoria militar en el campo de batalla. 


\section{Bibliografía}

" Abad de Santillán, D. (1940). Por qué perdimos la guerra. Una contribución a la historia de la tragedia española. Editorial Gregorio del Toro.

" ACTA DEL COMITÉ CENTRAL DE MILICIAS ANTIFASCISTAS (03/08/1936). ATMT, Fondo Tarradellas

» ACTA DEL COMITÉ CENTRAL DE MILICIAS ANTIFASCISTAS (31/08/1936). AMTM, Fondo Tarradellas.

" ACTAS DEL COMitÉ CENTRAL DE MILICIAS ANTIFASCISTAS (04/09/1936). AMTM, Fondo Tarradellas.

" ACTAS DEL CONSEJO EJECUTIVO DE LA GENERALITAT DE CATALUNYA (11/11/1936). AGMAV, Fondo 1.2, Instituciones de la Administración Territorial, Generalitat de Catalunya.

" ACTAS DEL CONSELL EXECUTIU DE LA GENERALITAT DE CATALUNYA (18/11/1936). AGMAV, Fondo 1.2, Instituciones de la Administración Territorial, Generalitat de Catalunya.

" ACTAS DEL CONSELL EXECUTIU DE LA GENERALITAT DE CATALUNYA (25/11/1936). AGMAV, Fondo 1.2, Instituciones de la Administración Territorial, Generalitat de Catalunya.

" ACTAS DEL CONSELL EXECUTIU DE LA GENERALITAT DE CATALUNYA (02/12/1936). AGMAV, Fondo 1.2, Instituciones de la Administración Territorial, Generalitat de Catalunya.

" ACTAS DEL CONSEJO EJECUTIVO DE LA GENERALITAT DE CATALUNYA (13/11/1936). AGMAV, Fondo 1.2, Instituciones de la Administración Territorial, Generalitat de Catalunya.

" ACTAS DEL CONSEJO EJECUTIVO DE LA GENERALITAT DE CATALUNYA (25/11/1936). AGMAV, Fondo 1.2, Instituciones de la Administración Territorial, Generalitat de Catalunya

" ACTAS DEL CONSEJO EJECUTIVO DE LA GENERALITAT DE CATALUNYA (02/12/1936). AGMAV, Fondo 1.2, Instituciones de la Administración Territorial, Generalitat de Catalunya.

" Aguilera, M. (2012). Compañeros y Camaradas: Las luchas entre antifascistas en la Guerra Civil española. Actas.

" Alcofar Nassaes, J. L. (s/fecha). La euforia revolucionaria y la formación de las columnas. Archivo del Pabellón de la República, Fondo José Luis Infiesta ALEGRE, D. (2018). La batalla de Teruel. Guerra total en España. La Esfera de los Libros.

" ARCHIVO DEL PABELLÓN DE LA REPÚBLICA, Fondo José del Barrio, Fondo José Luis Infiesta. Barcelona, España.

" ARCHIVO GENERAL MILITAR DE ÁVILA (AGMAV), Fondo 1.2, Instituciones de la Administración Terriotial, Generalitat de Catalunya. Ávila, España

" ARCHIVO MONTSERRAT TERRADELLAS I MECIA (AMTM), Fondo Tarradellas. Vimbodí, España.

" ARCHIVO NACIONAL DE CATALUÑA (ANC), PS-Barcelona Generalitat. Barcelona, España

" AUTO DEL COMITÉ CENTRAL DE MILICIAS ANTIFASCISTAS (08/09/1936). ATMT, Fondo Tarradellas

" Berger, G. (2018). Les milíciesantifeixistes de Catalunya. Voluntaris per la llibertat.Eumo. 
" BOLETÍN OfICIAL DE LA GENERALITAT DE CATALUÑA. 21/07/1936

"Cenarro, Á. y Pardo, V. (2006). Guerra Civil en Aragón 70 años después. Centro del libro de Aragón: Gobierno de Aragón.

" CENTRO DOCUMENTAL DE LA MEMORIA HISTÓRICA (CDMH), Delegación Nacional de Servicios Documentales de la Presidencia de Gobierno. Fondo PS_BARCELONA, Fondo PS_Madrid. Salamanca, España.

" CONSEJERÍA DE DEFENSA DE LA GENERALITAT (21/11/1936). Estado genérico del movimiento de caudales y cálculos de Crédito para terminar el mes. AMTM, Fondo Tarradellas.

" DETALLE DEL TOTAL DE FACTURAS ENTRADAS HASTA LA FECHA (21/04/1937). AMTM, Fondo Tarradellas.

" DIARIO DE OPERACIONES DEL CORONEL JOSÉ LUIS GARCÍA RUIZ (08/10/1936). AGMAV, Fondo Ejército Nacional, Capitanía de Palma de Mallorca.

" DIARIO DE OPERACIONES DE LA BATERÍA LIGERA DE LA COLUMNA DURRUTI, FRENTE DE MADRID (14/05/1937). IISH, Fondo CNT 94H.

"Feldman, F. (1956). A Life in the twilight. Inédito.

" GACETA DE MADRID

"Garcia Oliver, J. (1978).El eco de los pasos. Editorial Ruedo Ibérico.

" Guarner, V. (1980). L'aixecament militar i la guerra civil a Catalunya (1936-1939). Publicacionsl'Abadia de Montserrat.

" INFORME DEL BARRIO AL COMITÉ DE GUERRA PSUC-UGT (24/09/1936). Archivo del Pabellón de la República, Fondo José del Barrio.

" INFORME DE JOSÉ DEL BARRIO AL COMITÉ DE GUERRA PSUC-UGT (27/10/1936). Archivo del Pabellón de la República, Fondo José del Barrio.

" INFORME DEL COMISARIO DE CARBONES DEL DEPARTAMENTO DE ECONOMÍA Y SERVICIOS PÚBLICOS DE LA GENERALITAT (03/03/1937). CDMH, Delegación Nacional de Servicios Documentales de la Presidencia del Gobierno, Fondo Barcelona Generalitat.

" INFORME DEL CORONEL COMANDANTE PRINCIPAL DEL DEPARTAMENTO TÉCNICO DE ARTILLERÍA AL CONSELLER DE DEFENSA (27/02/1937). CDMH, Delegación Nacional de Servicios Documentales de la Presidencia del Gobierno, Fondo Barcelona Generalitat.

" INSTITUTO INTERNACIONAL DE HISTORIA SOCIAL (IISH), Fondo CNT. Ámsterdam, Países Bajos.

" Krivitsky, W. (1946). La mano de Stalin sobre España. Editorial Claridad.

" Magnus, H. (1998). El corto verano de la anarquía. Vida y muerte de Durruti. Editorial Anagrama.

" REGLAMENTO INTERNO DE LAS MILICIAS ANTIFASCISTAS DE CATALUÑA (22/07/1936). CDMH, Delegación Nacional de Servicios Documentales de la Presidencia del Gobierno. PS_BARCELONA_11,2.

" RELACIÓN DE DONATIVOS INGRESADOS EN EL COMITÉ DE MILICIAS ANTIFASCISTAS, Acumulado 25/08/1936, 09/09/1936, 16/09/1936, 21/11/1936. CDMH, Delegación Nacional de Servicios Documentales de la Presidencia de Gobierno, PS-BARCELONA_ GENERALITAT_PS_BARCELONA, 69. 9. ROJO, V. (1940). España heroica.Diez bocetos de la guerra española. El Sol. 


\section{Sobre el autor}

Gonzalo Berger Mulattieri es docente universitario (TC-UPF y UOC) y miembro del grupo de investigación Nexus-UPF. Publicó su tesis doctoral bajo el título de Las milicias antifascistas de Cataluña. Voluntarios por la libertad (2018). Autor de varios libros, artículos y monografías, está especializado en la Guerra Civil española y el fenómeno del voluntariado en los conflictos europeos contemporáneos. Es investigador principal de los proyectos "Las Milicias antifascistas de Cataluña" (Archivo Nacional de Cataluña) y "Mujeres en guerra: vida y legado de las mujeres combatientes en la Guerra Civil Española" (P06420 - Memoria Democrática-120-MD-2020) y codirector del proyecto "Espacios de la Batalla de Mallorca". Recientemente fue coordinador del proyecto "Museo Virtual de la Mujer Combatiente" (Ministerio de la Presidencia y Memoria Democrática), comisario de la exposición "No pasarán. 16 días, Madrid 1936" (Ayto. de Madrid) y guionista de los documentales "Milicianas" (TV3) y "Las Sinsombrero 3. Las exiliadas" (RTVE).

(D)https://orcid.org/0000-0002-3905-6998

\section{About the author}

Gonzalo Berger Mulattieri is a University Professor (TC-UPF and UOC) and a member of the Nexus-UPF research group. He published his doctoral thesis under the title Las miliciasantifascistas de Cataluña. Voluntarios por la libertad(2018). Author of several books, articles and monographs, he specializes in the Spanish Civil War and the phenomenon of volunteering in contemporary European conflicts. He is principal researcher in the projects"Las Milicias antifascistas de Cataluña" (Archivo Nacional de Cataluña) and "Mujeres en guerra: vida y legado de las mujeres combatientes en la Guerra Civil Española" (P06420 - Memoria Democrática120-MD-2020) and co-directorof the project "Espacios de la Batalla de Mallorca".Recently he wascoordinatorof the project "Museo Virtual de la Mujer Combatiente" (Ministerio de la Presidencia y Memoria Democrática), curatorof the exhibition "No pasarán. 16 días, Madrid 1936" (Ayto. de Madrid) and screenwriterof the documentaries "Milicianas" (TV3) and "Las Sinsombrero 3. Las exiliadas" (RTVE). 